\title{
Plasma Physics Division Progress Report
}

B. Lehnert

Chairman, Plasma Physics Division

The pre-history of the Plasma Physics Division of the European Physical Society and the work of the Board of the Division during the period from June 1969 to January 1970 are summarized in this report.

\section{Formation of the Plasma Physics Division}

Some thirty years ago plasma physics appeared to be a rather limited and specialized branch of physics. However, it soon became obvious that the interaction between electrically conducting matter and electromagnetic fields constitutes an important field of research with a great number of implications in such fields as cosmic physics, controlled thermonuclear fusion, magnetohydrodynamic power generation, plasma chemistry and a number of technical problems involving gaseous discharges. In fact, plasma physics describes the "fourth state of matter" which includes practically the whole field of classical physics, and also considerable parts of atomic and nuclear physics. In addition to its applications, plasma research therefore serves the important task of deepening the understanding of physics as a whole. Because of its many-sidedness it stimulates and enriches the interaction between different branches of physics and between basic research and technical development. These facts will influence the way in which the Division plans its future work, since a link exists between its scientific and organizational matters.

International conferences and symposia on plasma physics and on its application to cosmic phenomena and controlled thermonuclear fusion have been organized with increasing frequency and on an increasing scale from the beginning of 1950. As has already been reported in an earlier issue of Europhysics News (No. 5 September 1969), these meetings were later transformed into a series of European Conferences on Controlled Fusion and Plasma Physics held in Munich (1966), Stockholm (1967) and Utrecht (1969).

At the Utrecht Conference the Plasma Physics Committee decided to apply for the admission as a "Plasma Physics Division" within the European Physical Society. The application for admission was approved by the Council of the EPS on 14 July 1969.

The Plasma Physics Division now considers its major tasks as being to stimulate plasma research in Europe and scientific cooperation between institutes and laboratories of the member nations. The formation of the Division has been mainly through the initiative of fusion physicists. However, it is necessary that other branches of plasma physics soon take a more active part in the work of the Division, and become represented in a more adequate way within its Board.

\section{Rules of the Division}

A preliminary version of the Rules for the Plasma Physics Division is under preparation, being complementary to the Constitution and By-laws of the EPS and concerning activities which are specific to the Division. Such activities are connected with the coordination of the many existing subfields of plasma physics, with the system of electing members of the Board, and with the ways of organizing meetings and courses. Since there already exists a Constitution of the EPS and since a certain flexibility is needed for the organizational work, the special Rules of the Division should not contain more than is absolutely necessary.

\section{European Plasma Physics Journals}

There is a strong opinion among the members of the Plasma Physics Board that a satisfactory solution of the problem of the Europhysics Journals is one of the major tasks of the EPS. Especially in the field of plasma physics there is, for the moment, no European journal with the same reputation and popularity as, for example, "The Physics of Fluids" in the United States. As a consequence, many European authors prefer to send some of their most important contributions to journals published outside Europe.

The points raised on this problem during discussions within the Board (which also have been forwarded to the Chairman of the Publications Committee) can be summarized as follows:

(i) There is a strong need for one major European journal in plasma physics being associated with the EPS and having the same status and importance as "The Physics of Fluids". A journal which appears frequently and which has a large editorial board would be of considerable advantage.

(ii) The journal should cover basic plasma physics, as well as its applications to fusion research, cosmic physics and other subjects within the frame of plasma physics, but not ordinary fluid dynamics.

(iii) If possible the journal should not appear as a new periodical in addition to the already existing ones. It may result from the fusion of some existing journals, or from the reorganization of one of them.

(iv) The journals which might be taken into account here are, among 
others, "Plasma Physics", "Journal of Plasma Physics", "Physica", "Journal de Physique" and the journals of The Institute of Physics and The Physical Society, UK.

(v) It will be difficult from the economical point of view, and for other practical and psychological reasons, to achieve a fusion of several journals. A concentration on a single reorganized journal may therefore be the easiest solution.

\section{Meetings and Courses}

A further task of the Division is to organize conferences, symposia, schools, courses and informal meetings in collaboration with the local organizing committees. In this connection, the following points have been considered by the Board:

(i) Proposals about the time and place of European meetings and courses on plasma physics and its applications should be settled by the

\section{B. Lehnert}

(Photo CNRS)

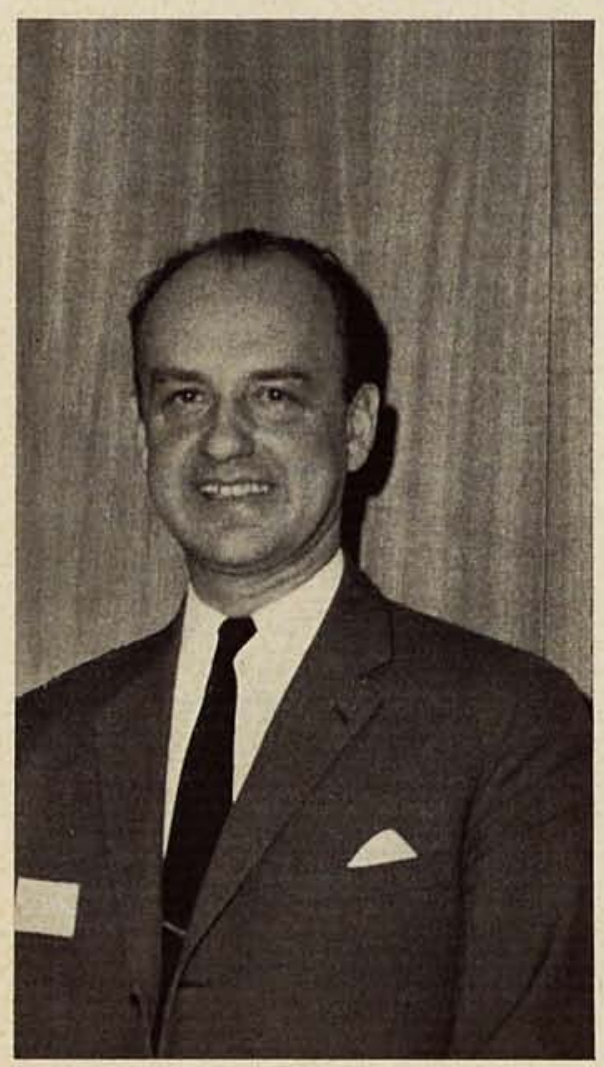

Board of the Division in collaboration with the local organizing committees in order to coordinate such activities inside as well as outside Europe.

(ii) The problem of fund-raising for plasma physics conferences sponsored by the EPS has to be considered.

(iii) The Conference Committee of the EPS has been sent a special note concerning the question whether the EPS should become more involved in the organization of open conferences on specialized subjects and should take the responsibility for the publication of abstracts or brief texts.

(iv) A Summer School on Plasma Physics has been proposed for 1971 or 1972 under the sponsorship of the EPS. For the financial arrangements, support may possibly be obtained from some special organization, in the same way as for the schools at "Les Houches" and "Varenna".

(v) During 1970 the following European meetings are held in plasma physics:

The "Fourth European Conference on Controlled Fusion and Plasma Physics" in Rome, Italy, 31 August to 4 September. The Chairman of the Organizing Committee is Professor B. Brunelli, c/o Laboratori Gas-Ionizzati, Casella Postale N. 65, I-00044 Frascati.

An informal symposium on "Dynamic Stabilization of Plasmas" in Lausanne, Switzerland, in early September. The Chairman of the Organizing Committee is E.S. Weibel, Centre de Recherches en Physique des Plasma, 21, avenue des Bains, CH-1000 Lausanne.

A "Conference on Electrical Discharges in Gases" in London, UK, 15-18 September. The organizers are the Institution of Electrical Engineers and The Institute of Physics and The Physical Society Conference Department; The Institution of Electrical Engineers, Savoy Place, London WC 2.

An "International Symposium on Solar-Terrestrial Physics" in Lenin- grad, USSR, in May. It is sponsored by IAU, IUGG/IAGA, URSI and COSPAR. Chairman of the Symposium Programme Committee is E.R. Dyer, c/o National Academy of Sciences, Washington, D.C. 20418, USA.

A symposium on plasma diagnostics held at Suchumi, USSR, 3-12 May, arranged by the Physical-Technical Institute in Suchumi (H.I. Leontev).

A school on plasma physics at Telavi, Gruz. USSR, starting at the end of September, arranged by the Physical Institute of the Academija Nauk, Toilisi (H.L. Tsintsadeze).

A symposium on laser plasmas in Moscow during the second half of November, arranged by the Physical Institute "P.H. Lebedev" (D.K. Akulina).

(vi) The Chairman of the Division has been in contact with the U.S. Atomic Energy Commission regarding the International Conference on Controlled Fusion and Plasma Physics to be held in USA in 1971 in collaboration with the International Atomic Energy Agency in Vienna.

(vii) There should be no European conference on controlled fusion in a year when there is a big international conference on the same subject. Some members of the Board have suggested that, during such a year, a European conference be organized covering another part of plasma physics, such as cosmic physics.

\section{Further coordination of European Research in Plasma Physics}

(i) The research group at Frascati in Italy is compiling a list of the work done by European plasma theoreticians. The possibility is being discussed of organizing a permanent exchange of information on this subject in the future, in connection with the Division.

(ii) It is desirable to compile a list of members of the Division in collaboration with the larger plasma physics institutes and laboratories in Europe. 